\title{
Longitudinal plasma metanephrines preceding pheochromocytoma diagnosis: a retrospective case-control serum repository study
}

\author{
S W Olson, S Yoon ${ }^{\dagger}$, T Baker ${ }^{1}$, L K Prince, D Oliver and K C Abbott ${ }^{2}$ \\ Department of Nephrology, Walter Reed National Military Medical Center, 8901 Rockville Pike, Bethesda, \\ Maryland 20889, USA, 'Department Chief, Joint Pathology Center, 606 Stephen Sitter Avenue, Silver Spring, \\ Maryland 20910, USA and ${ }^{2}$ The National Institute of Diabetes and Digestive and Kidney Diseases (NIDDK), \\ Bethesda, Maryland 20892, USA \\ ${ }^{\dagger}$ (Dr S Yoon has moved on to private practice)
}

Correspondence

should be addressed

to S W Olson

Email

Stephen.w.olson.mil @mail.mil

\begin{abstract}
Objective: Plasma metanephrines (PMN) are highly sensitive for diagnosis of pheochromocytoma, but the natural history of PMN before pheochromocytoma diagnosis has not been previously described. The aim of the study was to compare the progression of PMN before pheochromocytoma diagnosis to matched healthy and essential hypertension disease controls. Design: A retrospective case-control Department of Defense Serum Repository (DoDSR) study.

Methods: We performed a DoDSR study that compared three longitudinal pre-diagnostic PMN for 30 biopsy-proven pheochromocytoma cases to three longitudinal PMN for age, sex, race, and age of serum sample matched healthy and essential hypertension disease controls. Predominant metanephrine (MN) or normetanephrine (NMN) production was identified for each case and converted to a percentage of the upper limit of normal to allow analysis of all cases together. PMN were measured by Quest Diagnostics.

Results: The predominant plasma metanephrine (PPM) was $>100$ and $300 \%$ of the upper limit of normal a median of 6.6 and 4.1 years before diagnosis respectively. A greater percentage of pheochromocytoma patients had a PPM $>100$ and $>300 \%$ of the upper limit of normal compared with combined healthy and essential hypertension disease controls $<2,2-8$, and $>8$ years prior to diagnosis. For patients with a baseline PPM $90-300 \%$ of the upper limit of normal, a $25 \%$ rate of rise per year was $100 \%$ specific for pheochromocytoma.
\end{abstract}

Conclusions: PPMs elevate years before diagnosis which suggests that delayed diagnoses are common. For mild PMN elevations, follow-up longitudinal PMN trends may provide a highly specific and economical diagnostic tool.

\section{Introduction}

Pheochromocytomas are rare catecholamine-secreting neuroendocrine tumors associated with significant morbidity and mortality. Patients with a high pre-test probability for secondary hypertension, an incidentally discovered adrenal adenoma (incidentaloma), or a known hereditary predisposition are all at elevated risk for pheochromocytoma (1). But suggestive clinical features of a pheochromocytoma are often initially unappreciated with up to $50 \%$ diagnosed only at autopsy $(2,3)$.
An unknown pheochromocytoma is prone to medical or mechanical stimulation of a catastrophic catecholamine storm (4). Therefore, a missed or delayed diagnosis can increase risk of end-organ damage from hypertensive emergency, perioperative death, perinatal death, and inoperable metastatic disease $(5,6,7,8,9,10)$.

Plasma metanephrines (PMNs) are an ideal screening test with near $100 \%$ sensitivity but an inadequate confirmatory test with as low as $85 \%$ specificity depending (c) 2016 European Society of Endocrinology Printed in Great Britain
Published by Bioscientifica Ltd 
on compliance for adequate sampling $(11,12,13,14,15$, $16,17,18)$. Levels between one and three times normal are a diagnostic challenge. Multiple additional urine and serum tests only reduce overall specificity (19). Tumor growth over time has not been shown to differentiate between pheochromocytoma and benign adrenal adenoma (20). A metaiodobenzylguanidine scan is highly specific but with some variability (89-100\%) in addition to being expensive and not universally available $(21,22,23,24)$.

The natural history of PMN prior to pheochromocytoma could better quantify diagnostic delay and/or improve diagnostic specificity but has not been reported. We utilized the Department of Defense Serum Repository (DoDSR) to compare chronologic PMN in pheochromocytoma patients before diagnosis to age, sex, race, and age of serum matched healthy and essential hypertension disease controls.

\section{Methods}

\section{Design}

We performed a case-control DoDSR study comparing pre-diagnostic PMNs for 30 pheochromocytoma cases to 30 matched healthy and 26 matched essential hypertension disease controls. Comprehensive DoDSR research methodology is described in our previous publications $(25,26,27)$. Briefly, a query of the military electronic medical record for pheochromocytoma (ICD-9 code 227.0) revealed 96 cases from 2000 to 2009. After comprehensive chart review, 55 cases were excluded because they were dependents of active duty members without requirements to bank serum or they lacked documented tissue confirmation of pheochromocytoma. Of the 41 remaining cases, five bilateral, extra-adrenal, syndromic, and/or metastatic pheochromocytoma cases were excluded due to minimal power for independent analysis and to minimize confounding variables for solitary pheochromocytoma analysis. In total, 30 of the remaining 36 patients had multiple serum samples available in the DoDSR. Background clinical, laboratory, and imaging data were collected for each case when available.

The DoDSR was established in $\sim 1985$. Each active duty service member has serum banked at entry into the military after passing a comprehensive medical screening exam. Additional samples are banked approximately biannually at the time of HIV screening in addition to before and after deployments. Additional clinical information is documented at required yearly medical screenings. Samples are stored at $-70{ }^{\circ} \mathrm{C}$ with no scheduled freeze/thaw cycles after banking. The freezers are monitored continuously. Approximately two million samples are now stored yearly, and the DoDSR currently has up to 60 million samples stored in Silver Spring, MD.

The DoDSR identified one age, sex, race, and age of serum sample matched healthy and essential hypertension disease control. Essential hypertension disease controls had an ICD-9 code for 401.9 without any secondary hypertension, malignant hypertension, or adrenal adenoma ICD-9 codes. The DoDSR then sent the oldest, second-to-last, and most recent $0.5 \mathrm{ml}$ samples prior to pheochromocytoma diagnosis along with matching control samples to Quest Diagnostics Nichols Institute (Chantilly, VA, USA) for measurement of PMN. PMN measurements were made by liquid chromatography and tandem mass spectrometry which is more accurate than enzyme immunoassay (EIA) (28). The upper limit of normal for metanephrine (MN) and normetanephrine (NMN) were 57 and $144 \mathrm{ng} / \mathrm{ml}$ respectively. Inter- and intra-assay variability were both $<10 \%$. Results were automatically calculated by Analyst Software (Quest Diagnostics). Data were analyzed for $\mathrm{MN}$ and NMN levels.

\section{Statistical analysis}

Each NMN and MN level was divided by 148 and 57 pg/ml respectively to establish comparable 'normalized' percent of the upper limit of normal values (\%ULNV). Each pheochromocytoma case was then classified as NMN or MN predominant based on the highest \%ULNV. MN and NMN predominant cases were then combined together for statistical analysis with only the predominant plasma metanephrines (PPMs) \%ULNV data used for comparison with combined matching controls. A similar model (free light chain difference (FLC diff)) is widely accepted to study a combination of $\kappa$ and $\lambda$ predominant $\mathrm{AL}$ amyloidosis cases (29). But, the \%ULNV is required to adjust $\mathrm{MN}$ and NMN because they do not have the same normal ranges. Healthy and disease controls were combined for data analysis because there was no statistically significant difference between the two controls in any time period.

The percent of pheochromocytoma cases with PPM $>100,200$, and 300\% ULNV were compared to combined healthy and essential hypertension disease controls at all times, $<2,2-8$, and $>8$ years prior to diagnosis. Not all patients had samples available for each subgroup time period. When a patient had multiple serum samples during a given time period, highest PPM determined 
Table 1 Background information presented for pheochromocytoma patients. Five patients were diagnosed after an adrenal mass was noted incidentally on imaging from an unrelated evaluation. Incidence of symptoms likely underestimated due to incomplete history available for patients who initially presented in the ICU and/or civilian hospitals. Information for each variable was not present in the electronic medical record for all study patients. Continuous variables (interquartiles), categorical variables (ratios).

\begin{tabular}{l} 
Age (years) \\
Gender (male) \\
Race (Caucasian) \\
Size (cm) \\
Location (right) \\
Diagnosis PPM \%ULNV, $n=16$ \\
Palpitations \\
Headache \\
Diaphoresis/flushing \\
Dizziness \\
Tremor \\
Pallor \\
Nausea/abdominal discomfort \\
Anxiety \\
Fatigue \\
Hyperglycemia \\
Hypertension before diagnosis \\
(months), $n=22$ \\
Sx before diagnosis (months), $n=18$ \\
Multisystem organ failure/hypertensive \\
$\quad$ emergency \\
Incidental discovery on imaging \\
\hline
\end{tabular}

$43(35,50)$
$93 \%$
$62 \%$
$4.5(3.4,6.0)$
$54 \%$
$940 \%(392,2212 \%)$
$68 \%(19 / 28)$
$57 \%(16 / 28)$
$32 \%(9 / 29)$
$29 \%(8 / 28)$
$14 \%(4 / 28)$
$11 \%(3 / 28)$
$18 \%(5 / 28)$
$14 \%(4 / 28)$
$21 \%(6 / 28)$
$29 \%(8 / 28)$
$27(6,48)$
$6(2,31)$
$14(4 / 33)$
$15 \%$

group assignment. The PPM percent change per year before pheochromocytoma diagnosis was compared to a combination of both healthy and essential hypertension disease controls. For example, percent change per year was calculated by dividing the most recent PPM (PPMr) by the oldest index PPM (PPMi), subtracting 1 and then multiplying by 100 . This value was then divided by difference in days between the two samples $(\mathrm{T} l-\mathrm{T} i)$ and multiplied by 365 days/year ((PPMr/PPMi-1)×100/Tl-Ti) $\times 365$. PPM doubling time was calculated by $((\mathrm{T} l-\mathrm{T} i) \times \log (2)) /$ (logPPMr-logPPMi). Because the data were not normally distributed, continuous variables for both cases and controls are reported with median values with interquartiles (25 and 75\%), and Wilcoxon-Mann-Whitney test was used to evaluate statistical significance. Categorical variables for cases and controls were compared using the Fisher's exact test because some comparison groups had less than five subjects. PPM $>100 \%$ ULNV receiver operating characteristic (ROC) curves were constructed for pheochromocytoma vs combined controls $<2,2-8$, and $>8$ years before diagnosis. $\mathrm{MN}$ and $\mathrm{NMN}$ line graphs were formed for all cases and combined controls. All data were analyzed with STATA 12.1 (Stata Corp., College Station, TX, USA). This study was approved by the Human Use Committee at Walter Reed National Military Medical Center, and informed consent was waived.

\section{Results}

\section{Demographics}

The majority of study cases were Caucasian males under 50 years old. The most common symptoms were palpitations, headache, and diaphoresis (Table 1). The longitudinal pre-diagnostic MN and NMN for each pheochromocytoma case and matched controls are presented via line graphs (Fig. 1). There were 21 pheochromocytoma cases that were NMN predominant and nine cases that were $\mathrm{MN}$ predominant.

Pheochromocytoma patients developed PPM >100, 200 , and $>300 \%$ ULNV years prior to diagnosis (Table 2). This delay between suggestive serologic diagnosis and clinical diagnosis is underestimated. The majority $(16 / 30)$ of cases had PPM $>100 \%$ ULNV in the oldest index sample, and there was a median 11 years between normal PPMi and elevated PPM in the second sample for the remaining 14 cases. Therefore, each case had an elevated PPM for a longer interval of unknown duration before diagnosis. A greater percentage of pheochromocytoma patients had an elevated PPM > 100, 200, and 300\% ULNV
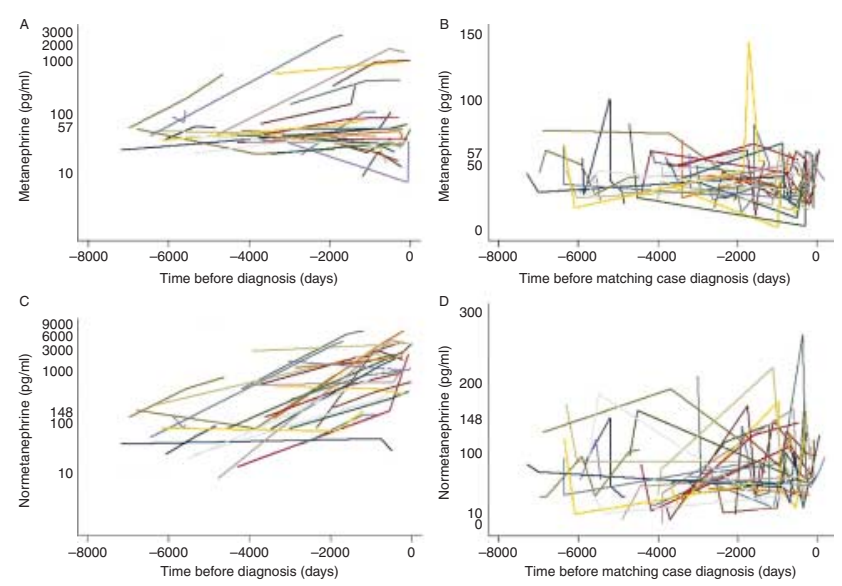

\section{Figure 1}

Line graphs demonstrating longitudinal pre-diagnostic changes in $\mathrm{MN}$ for pheochromocytoma cases (A) and controls (B) as well as NMN for pheochromocytoma cases (C) and controls (D). A full colour version of this figure is available at http://dx.doi.org/10.1530/EJE-15-0651. 
Table 2 Median time for PPM to surpass 100, 200, and 300\% ULNV before pheochromocytoma diagnosis.

\begin{tabular}{lcc}
\hline $\begin{array}{l}\text { PPM (\% upper limit } \\
\text { of normal) }\end{array}$ & $\begin{array}{c}\text { Time to surpass } \\
\text { threshold } \\
\text { (median years) }\end{array}$ & $\begin{array}{c}\text { Interquartile range } \\
(25 \text { and } 75 \% \text { years })\end{array}$ \\
\cline { 1 - 1 }$>100 \%(n=30)$ & 6.6 & $2.5,10.8$ \\
$>200 \%(n=28)$ & 5.2 & $2.1,9.2$ \\
$>300 \%(n=25)$ & 4.1 & $2.0,8.3$ \\
\hline
\end{tabular}

compared with combined healthy and essential hypertension disease controls at any time, $<2,2-8$, and $>8$ years before diagnosis (Table 3 ).

More pheochromocytoma cases had a PPM rate of rise per year $>0 \%(100 \%$ vs $54 \% ; P \leq 0.001),>10 \%$ (87\% vs $23 \%, P<0.001),>50 \%(53 \%$ vs $5 \% ; P<0.001)$, and $>150 \%$ (33\% vs $0 \% ; P<0.001)$ than combined healthy and essential hypertension disease controls. But, a rise in PPM over time within the normal range accounted for the majority of these positive controls. The longitudinal trend for PPMi within the diagnostically challenging range of $90-300 \%$ ULNV could have more practical clinical relevance. For patients with a PPMi between 90 and 300\%, a subsequent rate of rise $>25 \%$ /year was $100 \%$ specific for future pheochromocytoma (Table 4). The median PPM percent rise per year for pheochromocytoma cases was $38 \%$ (interquartiles 6 and 58\%). The median time between index PPM 90 and 300\% ULNV and a PPM > 300\% ULNV was 5 years. But, this is an overestimation because, all but one, the PPM became $>300 \%$ ULNV between the oldest index and second-to-last sample which had the longest time interval. All six cases with available time intervals $<3$ years crossed the $>300 \%$ ULNV value. The median doubling time for PPM was 3.1 years (interquartiles 2.0 and 5.8 years). In total, $50 \%$ of cases had a doubling time $2.0-4.5$ years, $20 \%$ had a doubling time $\leq 1.5$ years, and $17 \%$ of cases had a doubling time $\geq 8$ years.

The pheochromocytoma vs combined healthy and essential hypertension disease controls PPM \%ULNV area under the ROC curve was 1.00 for $<2$ years, 0.95 for 2-8 years, and 0.77 for $>8$ years before diagnosis (Fig. 2).

\section{Discussion}

Our results describe the natural history of PMN prior to pheochromocytoma for the first time and provide multiple important observations.

First, the PPM became elevated and even surpassed the 300\% ULNV threshold for near 100\% diagnostic specificity, years prior to clinical diagnosis. Consistent with previous literature, this observation strongly suggests that a diagnostic delay is common and that timely consideration of the disease is paramount for a prompt diagnosis. A missed or delayed diagnosis can result in substantial morbidity and mortality particularly from mechanical or medicinal stimulation and wide-spread inoperable metastasis. The 'false positive' PPMs documented in the healthy and disease controls were likely due to non-optimal lab draw conditions. Non-compliant sampling results in $\sim 50 \%$ higher PMN in normal controls, but has no effect in pheochromocytoma patients (30). However, any overestimation of PPM in our controls would have only reduced the statistical significance of our results.

Secondly, the median PPM doubling time was $\sim 3$ years. To our knowledge, this is the first description of PPM doubling rates for apparently sporadic pheochromocytomas. Interestingly, there were three temporal subgroups that accounted for the majority of cases $(\leq 1.5,2-4.5$, and $\geq 8$ years). One interpretation is that pheochromocytoma genetic profiles impact tumor growth rates. Amar et al. (31) found that succinate dehydrogenase B gene mutation was associated with a shorter MN doubling time and worse survival in a cohort of metastatic pheochromocytomas. A future serum repository study that compares longitudinal pre-diagnostic PPM in pheochromocytomas with a multiple genetic profiles is required to address this hypothesis.

Table 3 Percent pheochromocytoma cases vs a combination of essential hypertension disease and healthy controls with PPM $>100,200$, and $300 \%$ of the upper limit of normal $(>57 \mathrm{ng} / \mathrm{ml}$ for $\mathrm{MN}$ and $>148 \mathrm{ng} / \mathrm{ml}$ for NMN) at all times, $<2,2-8$, and $>8$ years before diagnosis.

\begin{tabular}{|c|c|c|c|}
\hline $\begin{array}{l}\text { PPM (\% upper } \\
\text { limit of normal) }\end{array}$ & $\begin{array}{c}\text { Cases } \\
(n=30)(\%)\end{array}$ & $\begin{array}{c}\text { Combined } \\
\text { controls } \\
(n=56)(\%)\end{array}$ & $P$ value \\
\hline (>100\%): all time prior & $100(30 / 30)$ & $29(16 / 56)$ & $<0.001$ \\
\hline$<2$ years & $100(21 / 21)$ & $10(4 / 41)$ & $<0.001$ \\
\hline $2-8$ years & $100(20 / 20)$ & $11(4 / 37)$ & $<0.001$ \\
\hline$>8$ years & $50(12 / 24)$ & $20(9 / 45)$ & 0.01 \\
\hline (>200\%): all time prior & $93(28 / 30)$ & $2(1 / 56)$ & $<0.001$ \\
\hline$<2$ years & $100(21 / 21)$ & $0(0 / 41)$ & $<0.001$ \\
\hline $2-8$ years & $90(18 / 20)$ & $3(1 / 37)$ & $<0.001$ \\
\hline$>8$ years & $38(9 / 24)$ & $0(0 / 45)$ & $<0.001$ \\
\hline (>300\%): all time prior & $83(25 / 30)$ & $0(0 / 56)$ & $<0.001$ \\
\hline$<2$ years & $95(20 / 21)$ & $0(0 / 41)$ & $<0.001$ \\
\hline $2-8$ years & $80(16 / 20)$ & $0(0 / 37)$ & $<0.001$ \\
\hline$>8$ years & $29(7 / 24)$ & $0(0 / 45)$ & $<0.001$ \\
\hline
\end{tabular}


Table 4 A comparison between the percentage of pheochromocytoma cases with a baseline PPM between 90 and $300 \%$ of the upper limit of normal ( $>57 \mathrm{pg} / \mathrm{ml} \mathrm{MN}$ and $>148 \mathrm{NMN}$ ) that subsequently rise at rates above specified thresholds when compared to matched controls.

\begin{tabular}{|c|c|c|c|}
\hline PPM (\% rise/year) & Cases $(\%)$ & $\begin{array}{c}\text { Combined } \\
\text { controls }(\%)\end{array}$ & $P$ value \\
\hline$(>0 \%)$ & $94(15 / 16)$ & $5(1 / 20)$ & $<0.001$ \\
\hline$(>25 \%)$ & $81(13 / 16)$ & $0(0 / 20)$ & $<0.001$ \\
\hline$(>50 \%)$ & $50(8 / 16)$ & $0(0 / 20)$ & $<0.001$ \\
\hline
\end{tabular}

Finally, and possibly most significant, our data set suggests that diagnostically challenging patients with a PPM 90-300\% ULNV can be followed with serial labs to achieve better diagnostic specificity. A $>25 \%$ PPM rise/ year was $100 \%$ specific in our cohort. The time required for these cases to cross the $>300 \%$ ULNV threshold appeared to be $<5$ years and potentially even far less. These findings could eventually apply for defined biochemical surveillance periods in cohorts with genetic risk, an incidentaloma, or concern for secondary hypertension.

Knowledge of specific genetic risk associated with pheochromocytoma is rapidly expanding. Up to $30 \%$ of apparently sporadic and non-syndromic pheochromocytomas have a known susceptibility gene, and this number will likely continue to grow with future discoveries $(21,32$, 33). These patients may benefit from periodic biochemical surveillance for transformation to phenotypic disease. Incidentalomas are an additional clinical challenge. Up to $7 \%$ of people will develop an adrenal adenoma over their lifetime, and $\sim 5 \%$ of these are a pheochromocytoma $(10,34,35,36,37)$. Because most incidentalomas are benign, a biochemical diagnosis is required. Also, 10\% of hypertension patients have a secondary cause $(38,39)$. Only 3-6\% of these cases are diagnosed with pheochromocytoma $(40,41)$. The classic triad of symptoms is insufficient for diagnosis (42). Our pre-diagnostic PPM comparison data between pheochromocytoma cases and combined healthy/essential hypertension disease controls could provide a resource to better interpret ongoing serologic surveillance in these at-risk populations (43).

But, due to many limitations of this study, prospective confirmation with more accurate controls is required before any clinical implementation. The healthy controls in this study were not known to have any genetic or family risk factors. The essential hypertension disease controls were not known to have clinical concern for a secondary cause of hypertension. In addition, the intervals between the oldest index sample and the second oldest sample were often long due to the limitation of three samples for each subject. This made temporal estimations of certain threshold PPM \%ULNV less accurate. Serial biochemical studies in at-risk patients at fixed intervals over time would be superior.

Our study had generalized limitations related to retrospective case-control DoDSR studies covered in previous publications $(25,26,27)$. There are also additional study-specific limitations. Seasonal variations, phlebotomy position, rest period prior to blood draw, temporal relationship to exertion, caffeine and food consumption, nicotine use, and acetaminophen or prescription medications can all alter PMN $(19,44,45,46)$. These potential confounders were not regulated or accurately accounted for at each blood draw. However, our matching criteria for age and race accounted for these known confounding variables $(45,47)$. We were also unable to link the temporal relationship between pre-diagnostic PPM elevation and onset of disease-related symptoms. We cannot rule out the possibility that a healthy or disease control subsequently developed a pheochromocytoma. But, in addition to being rare, a case misattributed, as a control would only lessen the statistical significance of our findings. Samples were stored at $-80^{\circ} \mathrm{C}$ for months-years prior to evaluation. But, there is precedence for analysis of frozen samples, and there was no evidence of PMN degradation over time in our healthy control samples $(14,15)$. We were unable to assign an age, sex, race, and age of serum matched essential hypertension disease control for four cases. Reported PML rate of change over

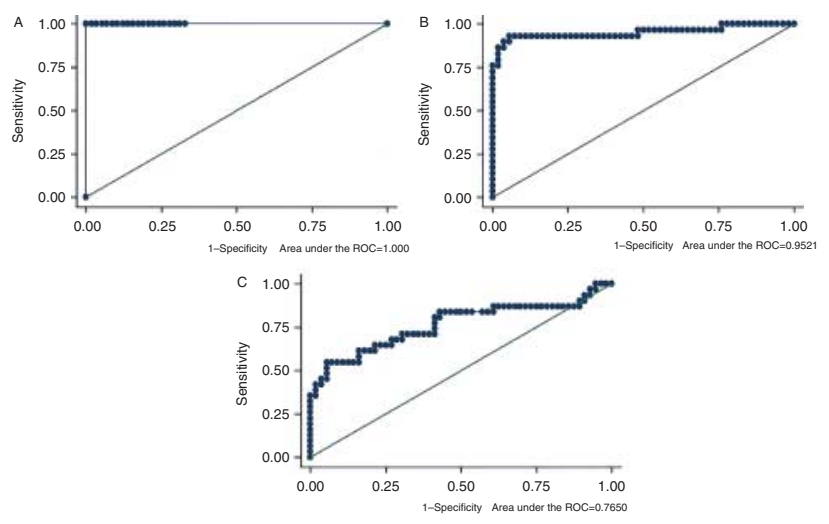

\section{Figure 2}

PPM $>100 \%$ ULNV receiver operating characteristic (ROC) curves for pheochromocytoma vs combined controls $<2$ years (A), 2-8 years (B), and $>8$ years (C) before diagnosis. A full colour version of this figure is available at http://dx.doi.org/10.1530/EJE-15-0651. 
time assumes a linear rise between oldest and most recent sample. This has not been proven. The scope of this study is limited by exclusion of metastatic, syndromic, extraadrenal, and bilateral pheochromocytomas. But future investigation could include a comparison of pre-diagnostic serologies in benign pheochromocytomas to metastatic pheochromocytomas (48). This study could potentially help better identify metastatic risk in at-risk populations under serologic surveillance.

Early diagnosis and definitive treatment of a pheochromocytoma mitigates substantial risk of morbidity and mortality. The need to better define longitudinal prediagnostic biochemical trends for improved surveillance has been previously proposed $(18,24)$. This data set addresses this important clinical need, but follow-up prospective confirmation is required prior to broad clinical implementation.

\section{Declaration of interest}

The authors declare that there is no conflict of interest that could be perceived as prejudicing the impartiality of the research reported. The views expressed in the manuscript are those of the authors and do not reflect the official policy of the Department of the Army, Department of Defense, or the US government.

Funding

This research did not receive any specific grant from any funding agency in the public, commercial or not-for-profit sector.

\section{References}

1 Lenders JW, Eisenhofer G, Mannelli M \& Pacak K. Phaeochromocytoma. Lancet 2005366 665-675. (doi:10.1016/S0140-6736(05)67139-5)

2 Manger WM. The protean manifestations of pheochromocytoma. Hormone and Metabolic Research 200941 658-663. (doi:10.1055/s-00281128139)

3 Manger WM. An overview of pheochromocytoma: history, current concepts, vagaries, and diagnostic challenges. Annals of the New York Academy of Sciences 20061073 1-20. (doi:10.1196/annals.1353.001)

4 Eisenhofer G, Rivers G, Rosas AL, Quezado Z, Manger WM \& Pacak K. Adverse drug reactions in patients with pheochromocytoma: incidence prevention and management. Drug Safety 200730 1031-1062. (doi:10.2165/00002018-200730110-00004)

5 Desai AS, Chutkaow WA, Edelman E, Economy KE \& Dec GW. A crisis in late pregnancy. New England Journal of Medicine 2009361 2271-2277. (doi:10.1056/NEJMcps0708258)

6 Kolomeyevskaya N, Blazo M, Van den Veyver I, Strehlow S \& Aagaard-Tillery KM. Pheochromocytoma and Von Hippel-Lindau in pregnancy. American Journal of Perinatology 201027 257-263. (doi:10.1055/s-0029-1239489)

7 Myklejord DJ. Undiagnosed pheochromocytoma: the anesthesiologist nightmare. Clinical Medicine \& Research 20042 59-62. (doi:10.3121/ cmr.2.1.59)
8 O'Riordan JA. Pheochromocytoma and anesthesia. International Anesthesiology Clinics 199735 99-127. (doi:10.1097/00004311199703540-00008)

9 Nomura K, Kimura H, Shimizu S, Kodama H, Okamoto T, Obara T \& Takano K. Survival of patients with metastatic malignant pheochromocytoma and efficacy of combined cyclophosphamide, vincristine, and dacarbazine chemotherapy. Journal of Clinical Endocrinology and Metabolism 200994 2850-2856. (doi:10.1210/jc.2008-2697)

10 Yu R, Nissen NN, Chopra P, Dhall D, Phillips E \& Weigh M. Diagnosis and treatment of pheochromocytoma in an academic hospital from 1997-2007. American Journal of Medicine 2009122 85-95. (doi:10.1016/ j.amjmed.2008.08.021)

11 Lenders JW, Pacak K, Walther MM, Linehan WM, Mannelli M, Friberg P, Keiser HR, Goldstein DS \& Eisenhofer G. Biochemical diagnosis of pheochromocytoma: which test is best? Journal of the American Medical Association 2002287 1427-1434.

12 Eisenhofer G, Lenders JW, Linehan WM, Walther MM, Goldstein DS \& Keiser HR. Plasma normetanephrine and metanephrine for detecting pheochromocytoma in Von-Hippel-Lindau disease and multiple endocrine neoplasia type 2. New England Journal of Medicine 1999340 1872-1879. (doi:10.1056/NEJM199906173402404)

13 Pacak K, Linehan WM, Eisenhofer G, Wlther MM \& Goldstein DS. Recent advances in genetics, diagnosis, localization, and treatment of pheochromocytoma. Annals of Internal Medicine 2001134 315-329. (doi:10.7326/0003-4819-134-4-200102200-00016)

14 Lenders JW, Keiser HR, Goldstein DS, Willemsen JJ, Friberg P, Jacobs MC, Kloppenborg PW, Thein T \& Eisenhofer G. Plasma metanephrines in the diagnosis of pheochromocytoma. Annals of Internal Medicine 1995123 101-109. (doi:10.7326/0003-4819-123-2199507150-00004)

15 Raber W, Raffesberg W, Bischof M, Scheuba C, Niederle B, Gasic S, Waldhausl W \& Roden M. Diagnostic efficacy of unconjugated plasma metanephrines for the detection of pheochromocytoma. Archives of Internal Medicine 200023 2957-2963. (doi:10.1001/archinte.160.19. 2957)

16 Eisenhofer G, Lenders JW \& Pacak K. Choice of biochemical test for diagnosis of pheochromocytoma: validation of plasma metanephrines. Current Hypertension Reports 20024 250-255. (doi:10.1007/s11906-0020015-4)

17 Sawka AM, Jaeschke R, Singh RJ \& Young WF. A comparison of biochemical tests for pheochromocytoma: measurement of fractionated plasma metanephrines compared with the combination of 24-hour urinary metanephrines and catecholamines. Journal of Clinical Endocrinology and Metabolism 200388 553-558. (doi:10.1210/jc.2002021251)

18 Yogish CK, Sawka AM \& Young WF. The laboratory diagnosis of adrenal pheochromocytoma: the Mayo clinical experience. Journal of Clinical Endocrinology and Metabolism 200388 4533-4539. (doi:10.1210/jc. 2003-030720)

19 Eisenhofer G, Goldstein DS, Walther MM, Friberg P, Lenders JW, Keiser HR \& Pacak K. Biochemical diagnosis of pheochromocytoma: how to distinguish true-from false-positive test results. Journal of Clinical Endocrinology and Metabolism 200388 2656-2666. (doi:10.1210/ jc.2002-030005)

$20 \mathrm{Yu}$ R \& Phillips E. Growth speed of sporadic pheochromocytoma. Clinical Endocrinology 201277 331-332. (doi:10.1111/j.1365-2265. 2012.04338.x)

21 Gimenez-Roqueplo AP, Caumont-Prim A, Houzard C, Hignette C, Hernigou A, Halimi P, Niccoli P, Leboulleux S, Amar L, Borson-Chazot F et al. Imaging work-up for screening of paraganglioma and pheochromocytoma in SDHx mutation carriers: a multicenter prospective study from the PGL.EVA investigators. Journal of Clinical Endocrinology and Metabolism 201398 E162-E173. (doi:10.1210/jc.2012-2975)

22 Timmers HJ, Taieb D \& Pacak K. Current and future anatomic and functional imaging approaches to pheochromocytoma and 
paraganglioma. Hormone and Metabolic Research 201244 367-372. (doi:10.1055/s-0031-1299712)

23 Berglund AS, Hulthen UL, Manhem P, Thorsson O, Wollmer P \& Tornquist C. Metaiodobenzylguanidine (MIBG) scintigraphy and computed tomography (CT) in clinical practice. Primary and secondary evaluation for localization of pheochromocytomas. Journal of Internal Medicine 2001249 247-251. (doi:10.1046/j.1365-2796.2001.00792.x)

24 Manger WM. Editorial: In search of pheochromocytoma. Journal of Clinical Endocrinology and Metabolism 200388 4080-4082. (doi:10.1210/ jc.2003-031234)

25 Olson SW, Arbogast CB, Baker TP, Owshalimpur D, Oliver DK, Abbott KC \& Yuan CM. Asymptomatic autoantibodies associate with future anti-glomerular basement membrane disease. Journal of the American Society of Nephrology 201122 1946-1952. (doi:10.1681/ASN. 2010090928)

26 Olson SW, Lee JJ, Prince LK, Baker TP, Papadopoulos P, Edison J \& Abbott KC. Elevated subclinical double-stranded DNA antibodies and future proliferative lupus nephritis. Clinical Journal of the American Society of Nephrology 20138 1702-1708. (doi:10.2215/CJN.01910213)

27 Olson SW, Owshalimpur D, Yuan CM, Arbogast C, Baker TP, Oliver D \& Abbott K. Relation between asymptomatic proteinase 3 antibodies and future granulomatosis with polyangiitis. Clinical Journal of the American Society of Nephrology 20138 1312-1318. (doi:10.2215/CJN.10411012)

28 Weismann D, Peitzsch M, Raida A, Prejbisz A, Gosk M, Riester A, Willenberg HS, Hlemn R, Manz G, Deutschbein T et al. Measurements of plasma metanephrines by immunoassay vs. liquid chromatography with tandem mass spectrometry of diagnosis of pheochromocytoma. European Journal of Endocrinology 2015172 251-260. (doi:10.1530/ EJE-14-0730)

29 Weiss BM, Hebreo J, Cordaro DV, Roschewski MJ, Baker TP, Abbott KC $\&$ Olson SW. Increased serum free light chains precede the presentation of amyloid light chain amyloidosis. Journal of Clinical Oncology 201432 2699-2704. (doi:10.1200/JCO.2013.50.0892)

30 Darr R, Pamporaki C, Peitzsch M, Miehle K, Prejbisz A, Peczkowska M, Weismann D, Beuschlein F, Sinnott R, Bornstein SR et al. Biochemical diagnosis of phaeochromocytoma using plasma-free normetanephrine, metanephrine, and methoxytyramine: importance of supine sampling under fasting conditions. Clinical Endocrinology 201480 478-486. (doi:10.1111/cen.12327)

31 Amar L, Baudin E, Burnichon N, Peyrard S, Silvera S, Bertherat J, Bertagna X, Schlumberger M, Jeunemaitre X, Gimenez-Roqueplo AP et al. Succinate dehydrogenase B gene mutations predict survival in patients with malignant pheochromocytomas or paragangliomas. Journal of Clinical Endocrinology and Metabolism 200792 3822-3828. (doi:10.1210/jc.2007-0709)

32 Pigney P \& Cardot-Bauters CC. Genetics of pheochromocytoma and paraganglioma: new developments. Annales d'Endocrinologie 201071 76-82. (doi:10.1016/j.ando.2009.11.004)

33 Lefebvre S, Borson-Chazot F, Boutry-Kryza N, Wion N, Schillo F, Peix JL, Brunaud L, Finat A, Calender A \& Giraud S. Screening of mutations in genes that predispose to hereditary paragangliomas and pheochromocytomas. Hormone and Metabolic Research 201244 334-338. (doi:10.1055/s-0032-1306308)

34 Young WF Jr. The incidentally discovered adrenal mass. New England Journal of Medicine 2007356 601-610. (doi:10.1056/NEJMcp065470)

35 Young WF Jr. Management approaches to adrenal incidentalomas: a view from Rochester, Minnesota. Endocrinology and Metabolism Clinics of North America 200029 159-185. (doi:10.1016/S0889-8529(05)70122-5)
36 Grumbach MM, Biller BM, Braunstein GD, Campbell KK, Carney A, Godley PA, Harris EL, Lee JK, Oertel YC, Posner MC et al. Management of the clinically inapparent adrenal mass ("incidentaloma"). Annals of Internal Medicine 2003138 424-429. (doi:10.7326/0003-4819-138-5-200303040-00013)

37 Bulow B \& Ahren B. Adrenal incidentaloma - experience of a standardized diagnostic programme in the Swedish prospective study. Journal of Internal Medicine 2002252 239-246. (doi:10.1046/j.13652796.2002.01028.x)

38 Moser M \& Setaro JF. Resistant or difficult-to-control hypertension. New England Journal of Medicine 2006355 385-392. (doi:10.1056/ NEJMcp041698)

39 Setaro JF \& Black HR. Refractory hypertension. New England Journal of Medicine 1992327 543-547. (doi:10.1056/NEJM19920820 3270808)

40 Martell N, Rodriguez-Cerrillo M, Grobbee DE, Lopez-Eady MD, Fernandez-Pinilla C, Mario A, Fernandez-Cruz A \& Luque M. High prevalence of secondary hypertension and insulin resistance in patients with refractory hypertension. Blood Pressure 200312 149-154. (doi:10.1080/08037050310009950)

41 Omura M, Saito J, Yamaguchi K, Kakuta Y \& Nishikawa T. Prospective study on the prevalence of secondary hypertension among hypertensive patients visiting a general outpatient clinic in Japan. Hypertension Research 200427 193-202. (doi:10.1291/hypres.27.193)

42 Stein PP \& Black HR. A simplified diagnostic approach to pheochromocytoma: a review of the literature and report of one institution's experience. Medicine 199170 46-66.

43 Binderup ML, Bisgaard ML, Harbud V, Moller HU, Gimsing S, Friss-Hansen L, Hansen TV, Bagi P, Knigge U, Kosteljanetz M et al. Von Hippel-Lindau disease (vHL). National clinical guideline for diagnosis and surveillance in Denmark. 3rd edition. Danish Medical Journal 201360 B4763.

44 Neary NM, King KS \& Pacak K. Drugs and pheochromocytoma - don't be fooled by every elevated metanephrine. New England Journal of Medicine 2011364 2268-2270. (doi:10.1056/NEJMc1101502)

45 Deutschbein T, Unger N, Jaeger A, Broecker-Preuss M, Mann K \& Petersenn S. Influence of various confounding variables and storage conditions on metanephrine and normetanephrine levels in plasma Clinical Endocrinology 201073 153-160. (doi:10.1111/j.1365-2265. 2009.03761.x)

46 Pamporaki C, Bursztyn M, Reimann M, Ziemssen T, Bornstein SR, Sweep FC, Timmers H, Lenders JW \& Eisenhofer G. Seasonal variation in plasma free normetanephrine concentrations: implications for biochemical diagnosis of pheochromocytoma. European Journal of Endocrinology 2014170 349-357. (doi:10.1530/EJE-13-0673)

47 Eisenhofer G, Lattke P, Herberg M, Siegert G, Qin N, Darr R, Hoyer J, Villringer A, Prejbisz A, Januszewicz A et al. Reference intervals for plasma free metanephrines with an age adjustment for normetanephrine for optimized laboratory testing of pheochromocytoma. Annals of Clinical Biochemistry 201350 62-69. (doi:10.1258/acb.2012. 012066)

48 Eisenhofer G, Lenders JW, Siegert G, Bornstein SR, Friberg P, Milosevic D, Mannelli M, Linehan WM, Adams K, Timmers HJ et al. Plasma methoxytyramine: a novel biomarker of metastatic pheochromocytoma and paraganglioma in relation to established risk factors of tumour size, location and SDHB mutation status. European Journal of Cancer 201248 1739-1749. (doi:10.1016/ j.ejca.2011.07.016)

Received 30 June 2015

Revised version received 9 December 2015

Accepted 15 December 2015 